\title{
Major Trends in the Digital Transformation of Agriculture
}

\author{
Zaripova Rimma \\ Kazan State Power Engineering University \\ Kazan, Russia \\ zarim@rambler.ru
}

Rocheva Olga

Kazan Cooperative Institute (branch) of the Russian University of the Cooperation

Kazan, Russia

rochevaolga@mail.ru

\author{
Tyurina Marina \\ Kazan National Research Technical University named after \\ A.N. Tupolev \\ Kazan, Russia \\ turina_m@mail.ru \\ Chupaev Andrey \\ Kazan National Research Technological University \\ Kazan, Russia \\ sautp@kstu.ru
}

\author{
Sharifullina Albina \\ Kazan National Research Technological University \\ Kazan, Russia \\ zarrimma@mail.ru
}

\begin{abstract}
The digitalization of the agro-industrial complex is a global process, during which the traditional way of agricultural production is replaced by a new one. Information resources are being formed, the collection, synthesis and adaptation of databases, applied software products and recommendations for improving the efficiency of agricultural production are taking place. The use of digital transformation technologies in agriculture is relevant and is becoming part of a competitive business.

The article describes the main trends in digital transformation in agriculture. The main trends in the use of intelligent innovations are precision farming technologies, cloud services of agricultural enterprise management, monitoring and accounting systems. The tasks and directions of digitalization of agricultural production have been defined. The research subject: relations, processes and mechanisms of digitization of agrarian sector of economy. Methods of research: analysis, synthesis, and generalization. Objective of the research: analysis of the current state of agricultural digitalization, identification of defining directions in the process of digital transformation and prospects of new technologies application in agriculture.
\end{abstract}

Keywords: digitalization, transformation, agriculture, agro-industrial complex, innovation, competitiveness, modernization, livestock breeding, Internet of things, big data

\section{INTRODUCTION}

The transformation of Russian agriculture into a competitive high-tech industry with high labor productivity and low non-productive costs requires a technological leap, an integral part of which is the introduction of digital technologies in agricultural production. Foreign developed countries are modernizing their economies and are rapidly developing innovative technologies using artificial intelligence, automation and digital platforms. To ensure the competitiveness of agriculture, it is necessary to accelerate digitalization using the latest information technologies. The Internet of Things is an effective tool in achieving a new level of digitalization. The program "Digitalization of Agriculture" being developed by the Ministry of Agriculture of Russia is aimed at increasing the level of technological development of agricultural production.

Agriculture is a sector of the economy focused on providing the population with food and obtaining raw materials for a number of industries. The industry is one of the most important and represented in almost all countries. An essential part of direct digitalization of processes is the applying of the Internet of things, the progress of applied mathematics, consulting and data processing. These tasks are implementable only with funding. 
including in the feed industry, is especially undeniable. Information technologies in the livestock industry are making considerable interest. Miniature sensors, which can be placed painlessly under the skin of animals and stay in their bodies for a long time without causing any harm, let people get the most complete information about livestock health and determine its current location. Information technology is also necessary to increase the yield in Russia.

\section{MATERIALS AND Methods}

Objectives of the digital transformation of agriculture are:

the transition to digital agriculture, precision farming, the active use of digital technologies in order to increase labor productivity;

- integration of manufacturer data flows and government data into the digitalization platform for agriculture to ensure global planning in the industry and provide accurate recommendations to market participants, also with use of artificial intelligence;

- the formation of mechanisms and support details for the implementation of digital technologies in agriculture;

- ensuring traceability of agricultural products (tags, chips, codes, identifiers, technologies, devices, systems);

- stimulating domestic development and providing access to various digital open platforms (digital field, herd, equipment management, greenhouses);

- providing a package of personal technological solutions for market participants;

- the implementation of online trading platforms and systems for the promotion of agricultural products.

The most urgent agricultural problem in the Russian Federation is a general technical and technological gap. In most cases, agricultural production is on the same level as it was in the 80 s of the last century. The innovative development of the agro-industrial complex is also slowed down due to the low level of technological equipment, which is largely determined by the technical and technological level of the industry and the insufficient qualifications of staff. While the world and European experience in agricultural work is already combined with information technology, in Russia this area is still not open widely.

Information technologies in agriculture help with solving a wide range of problems $[1,2]$. The implementation of modern information technologies in agriculture involves the constant enrichment of information from various external sources, for example, via the Internet from almost anywhere at any given time. The list of information technologies is very long: for example, there are such developments of information systems that warn farmers about the appearance of pests and plant diseases. The implementation of information technology also significantly reduces the impact of the human factor, which is a positive moment for the enterprise [3, 4]. Their role in the automation of the processes of agricultural enterprises,
Materials, methods and objects of research - regional and federal level of agro-industrial complex of the Russian Federation. At carrying out of researches information materials, sites where results of researches and data on digitization of agriculture are presented were used; their analysis and generalization was conducted. The level of introduction of digital technologies in agriculture still remains low. By this indicator Russia takes 15 th place in the world. It is predicted that by 2026 the market for information and computer technologies in agriculture should grow at least five times. An effective tool in achieving a new level of digitalization is the Internet of Things. As long as Russia occupies only $1.5 \%$ of the world's Internet of things, this figure is even lower in agriculture. The importance of accelerated development of the digitalization of Russian agriculture is conditioned by the need to drastically increase the efficiency of agricultural production and significantly reduce the number of workers needed to produce the required volumes of agricultural products. Foreign developed countries are rapidly developing innovative technologies using artificial intelligence, automation and digital platforms. Increasing labor productivity and ensuring the competitiveness of agriculture requires the introduction of digitalization based on the latest achievements in information technologies.

Developed countries are successfully modernizing their economies, developing innovative technologies in agriculture, where artificial intelligence, automation and digital platforms dominate, which gives them additional competitive advantages. In the Russian Federation, the greatest potential in agriculture will be possessed by technologies for monitoring, equipment management, precision farming, and a network of Internet-connected facilities capable of collecting data and exchanging information coming from built-in services. These tasks can be solved by introducing information technologies, combining the efforts of program developers, investors, specialists and authorities.

\section{RESULTS}

The main trends, as strategic guidelines, are the digital transformation of agriculture:

- precision farming: differentiated watering and sowing, fertilizing, crop forecasting;

- sensors for measuring the temperature and humidity of soil, air, products, a monitoring system for agricultural machinery and staff, control of fuels and lubricants and cattle; 
the maximum normalization of the environmental situation in certain regions of the Russian Federation. The automation of the agro-industrial complex is the solution for the food issues and the improvement of competitiveness. Modern mechanization and the development of information technologies, which allow each used unit of resources to obtain a greater quantity, variety and variety of high-quality food products - this is the most effective way to develop the agro-industrial complex.

Information technologies are needed in agriculture, ranging from tractor control using satellite technology to automation of large processing plants. The range of work for information technology is simply huge [9, 10]. Today, agricultural manufacturers understand that without the use of high-quality information technologies, they will not be able to reduce production costs. In this area, technology has already reached the highest level. Seeds, fertilizers, agricultural machinery - all production elements are so highly developed that the only factor due to which it is still possible to reduce costs is the use of new information technologies. Agricultural enterprises of Russia have recently begun to pay more attention to new technologies. Now, without information technology and without the use of modern methods of information analysis, it is impossible to survive in a competitive market. The use of new satellite technologies for monitoring yield, increasing soil fertility through accurate soil research and fertilizer use, the use of new digital weather stations allows you to achieve better results in the field of crop production.

Today, most large Russian agricultural enterprises use foreign information technologies. However, this situation cannot suit native manufacturers. Will Russian solutions, both in software and hardware, become competitive to foreign developments in the field of agriculture in the near future? It is unlikely that today domestic manufacturers will be able to abandon world experience, which is largely due to the use of modern equipment from world leaders in the field of agriculture. In fact, this is a forced situation: while developers of equipment in Russia cannot offer equipment that matches the characteristics of the tasks of manufacturers, they have to use equipment from well-known foreign developers [11].

However, there are positive trends in this direction. Tender results in the direction of information technology show a positive trend. Domestic solutions can be competitive in comparison with foreign ones: they have a lower cost and at the same time, they have an important characteristic - high scalability to other areas. They can be integrated into management systems: transport, logistics, food production, grain growing.

The practical application of "precision farming" was made possible due to the widespread use of electronic equipment software, the creation of remote and on-board sensors for actuating the executive automatic parts of machines and assemblies [12-14]. Accelerating the solution of problems to improve management in the agro-industrial complex using electronic equipment consists not only in increasing its financing, but also in training employees capable of creating and applying information technologies in agriculture,
Accounting and control of soil pollution are also monitored using information technology, which allows you to pay more attention to the well-being of the environment and 
including "precision agriculture". One of the signs of the use of information technology in farms is the availability of computers, as well as their connection to the Internet. In the progressive society, a farmer can connect to the Internet from anywhere in the world using powerful wireless communications. It monitors the necessary aspects of the functioning of the farm, as the means of mechanization and animals are equipped with miniature computers connected to the Internet. The farmer can install various types of sensors in the right places and have access to them at any time. Thus, he has access to all the required data.

The expansion of information databases is also an important condition for their effective use in farms. Initial information should be convenient for assessing biological and physical systems in order to develop useful knowledge about the current state of farms, as well as forecasting the results when implementing various options. The accumulated knowledge in agricultural research over the years should be applied to obtain practically useful information by processing databases.

Monitoring of the agro-industrial complex has significant differences from other consumers of information technology. This requires control not only of transport, but also of fertilizing, seedlings, weather conditions and compliance with sanitary standards. Since the food industry is closely related to human health, it is necessary to control literally everything in it to prevent poisoning or infection of the population. Therefore, in agriculture, the most diverse, sometimes unique monitoring systems are used. We have developed an information system for determining the chemical composition of liquids. Methods of analysis of chemical composition of liquids with the use of ion selective electrodes are among the most promising modern analytical techniques that allow to quickly and accurately determine the concentration of many ions. Convenience and simplicity of work with such electrodes contribute to their wide distribution and application in various fields: agriculture, ecology and other industrial fields. Application of ion selective electrodes allows to control automatically continuously the ionic composition of liquids. Thus, an automated system has been developed that allows to quickly and qualitatively measure the concentration of ions of several chemical elements simultaneously, as well as the $\mathrm{pH}$ value of the water environment [15-17].

The object of management in agriculture is the field. Monitoring its condition is most efficiently carried out using satellite imagery, and such solutions already exist. Satellite images allow you to assess the sown areas and determine the general condition of each specific field. This is useful mainly for state accounting and general statistics, since satellite images can be obtained no more than once a week, which is not suitable for operational decision-making [18-20]. At the same time, in order to get financial investments from banks and insurance companies to agricultural activities, there is a lack of officially confirmed information on the resources of enterprises, disaggregated by specific fields. There are pilot projects in individual regions where clear deadlines for reporting on the status of fields in winter and spring crops are defined. They manage to attract additional financial resources to agriculture. However, it is too early to speak about such decisions on a federal scale. However, for the rapid assessment of crops, you can use unmanned vehicles. They allow you to accurately assess the condition of plants, and such surveys can be carried out often and receive detailed information about seedlings for quick decision-making in order to have a better crop. Many large agricultural holdings in Russia have already bought several unmanned vehicles and are experimenting with their use.

The rise of smart agriculture is impossible without a competent partnership between the state and business. The digitalization level of agriculture can increase at least 3-4 times. It is estimated that the digitalization of agricultural production will allow farmers to reduce costs by $23 \%$. The possibilities of digital transformation in the economy are aimed at innovations in the information support of enterprises, the introduction of information technologies, as well as systems based on non-contact measurement and automatic photographic analysis using satellite, tax, export, climate, soil, land tenure and other information provided in established formats online, including the integration of objective data of agricultural producers. Automation of business processes largely determines the timeliness and effectiveness of management decisions at enterprises of all sizes and spheres of management [21]. Inaccessibility of modern means of mechanization and automation for the overwhelming majority of agricultural producers in Russia is the main reason for low labor productivity and, consequently, high unit production cost. Transition from the model of sale of agricultural machinery and automation means to the model of payment for their functions according to the actual volume or results of consumption solves the problem of availability of equipment and, consequently, increase of labor productivity.

Nowadays, events are already taking place in Russia aimed at improving the efficiency of information and consulting services for the agro-industrial complex, promoting its sustainable development on the basis of scientific and technological progress, creating favorable conditions to meet the needs of managers and specialists of agricultural enterprises of all forms of ownership, farmers in obtaining knowledge about the latest achievements of domestic and world agricultural science, technology and technology, advanced domestic and foreign experience. Such direction as providing an information, consulting, technical and expert, organizational and managerial services and assistance in the selection and development of innovative technologies, preparation, development and implementation of investment projects, organization of production, is developing successfully. Information resources are being formed, the collection, synthesis and adaptation of databases, applied software products and recommendations for improving the efficiency of agricultural production are taking place [22].

The results of the study led to the conclusion that the implementation of measures to digitalize agriculture will ensure:

- reducing the gap in agricultural productivity between the levels of developed countries;

- increase the attractiveness of the industry for investors, entrepreneurs and workers; 
[5] "Farm Beats: AI and IoT", for Agriculture Established, May 14, 2015 [Electronic resource]. Available at: https://www.microsoft.com/enus/research/project/farmbeats-iot-agriculture.

- $\quad$ increasing the competitiveness and wages of workers;

- increasing demand for domestic machine-building products and domestic innovations;

- agricultural science development;

- emergence of a large number of companies that develop innovative services for agriculture.

Thus, if government, science and business combine their efforts, the result will be an opportunity to create one of the most innovative industries not only in Russia, but also in the whole world.

\section{CONCLUSION}

Information technology can provide significant assistance in solving a large number of tasks related to the planning, forecasting, analysis and modeling of agricultural processes in order to increase the competitiveness of the business. In general, as part of the digital transformation, many information platforms should be created, most of which should be open to industry participants. This should accelerate the introduction of digitalization in the agro-industrial complex, ensure competition between IT companies and consulting agencies, and ensure the reliability of data turnover in agriculture.

Digital technology will become an integral part of agriculture in the near future, from crop planning, irrigation automation and digital crop modeling to the calculation of cattle forage. The transformation of the agro-industrial complex of the Russian Federation presupposes digitalization of all areas of agricultural production: plant growing, animal breeding, fishing, poultry farming, breeding and genetics, greenhouse industry, etc.

It should be noted that the digital transformation of agriculture is only beginning to gain momentum, so it is impossible to predict what the industry will look like, for example, in 15-20 years. However, it is obvious that all market players will receive the effects of the digital transformation of the industry.

\section{REFERENCES}

[1] "Implementing UN/CEFACT e-Business standards in Agricultural Trade", Official Website of United Nations Economic Commission for Europe [Electronic resource]. Available at: https:// www.unece.org.

[2] R. Bokusheva, H. Hockmann, and S.C.Kumbhakar, "Dynamics of productivity and technical efficiency in russian agriculture", European review of agricultural economics, 2012, vol. 39, no. 4, pp. 611-637.

[3] R. S. Zaripova, R. R. Galyamov, and A. Yu. Sharifullina, "Organization of production in a digital economy" in Science of Krasnoyarsk, 2019 , vol. 8, no. 1-2, pp. 20-23.

[4] A. R. Salyakhov, R. S. Zaripova, and A. V. Chupaev, "Development of an automated system for managing the activities of an agricultural enterprise in a digital economy", in Siberian Journal of Life Sciences and Agriculture, 2019, vol. 11, no. 2-2, pp. 75-78. Design, 2017 [Electronic resource]. Available at: http://www.electronicdesign.com/analog/3-ways-iot-revolutionizesfarming. Smarts, April 30, 2018 [Electronic resource]. Available at: http://syntheticsmarts.com/artificial-intellgence-agriculture/.

[8] C. Schmitz, A. Popp, H. van Meijl, A. Tabeau, A. Kaval-lari, P. Kyle M. Wise, G. C. Nelson, D. M. d'Croz, S. Fujimori, T. Hasegawa, A. Gurgel, P. Havlik, H. Valin, E. Heyhoe, R. Sands, D. van der Mensbrugghe, M. von Lampe, and E. Blanc, "Land-use change trajectories up to 2050: insights from a global agro-economic model comparison", Agricultural economics, 2014, vol. 45, no. 1, pp. 69-84.

[9] R. S. Zaripova and S. P. Mironov, "The process of managing the innovative activities of organizations in the transition to the digital economy", in Science of Krasnoyarsk, 2018, vol. 7, no. 2-2, pp. 25-29.

[10] "OECD", Key Issues for Digital Transformation in the G20, Berlin 2017 [Electronic resource]. Available at: https://www.oecd.org/g20/keyissues-for-digital-transformation-in-the-g20.pdf

[11] T. S. Antipova and R. S. Zaripova, "Prospects and problems of import substitution of information technologies in Russia", in Science of Krasnoyarsk, 2019, vol. 8, no. 4-4, pp. 11-14.

[12] L. V. Plotnikova, E. E. Kostyleva, I. I. Chilikova, and S. Y. Sitnikov, "The use of heat pump installations as part of waste energy convertion complexes in the joint generation of electrical and thermal energy 2019", IOP Conference Series: Earth and Environmental Science, International Scientific Conference "Efficient waste treatment - 2018", vol. 337, $012058 \mathrm{p}$.

[13] L. V. Plotnikova, R. R. Giniyatov, S. Y. Sitnikov, M. A. Fedorov, and R. S. Zaripova, "Perfection of the methodology for developing industrial secondary energy generation systems", IOP Conference Series: Earth and Environmental Science, 2019, vol. 288, 012069 p.

[14] L.V. Plotnikova, and L. A. Kashipova, "Development of software for analysis of the structure of industrial heat and power systems", Source of the Document 2016 2nd International Conference on Industrial Engineering, Applications and Manufacturing, ICIEAM 2016, 7911675 $\mathrm{p}$

[15] R. S. Zaripova, E. A. Saltanaeva, N. G. Bikeeva, and E. V. Priimak, "Development of quality monitoring devices for industrial water in heat supply systems", IOP Conference Series: Earth and Environmental Science, 2019, vol. 288, 012129 p.

[16] R. Zaripova and V. Belavin, "The number of higher educationa institutions", Problems of energetics, Kazan: Kazan State Power Engineering University, 2006, vol. 3-4, pp 93-98.

[17] L. Belyaeva, R. Zaripova, Y. Petrushenko, and E. Popov, "The number of higher educational institutions", Problems of energetics, Kazan: Kazan State Power Engineering University, 2011, vol. 1-2, pp. 119-126.

[18] N. K. Petrova and H. Hanada, "Computer simulating of stellar tracks for observations with the lunar polar telescope", Planetary and Space Science, 2012, vol. 68, pp $86-93$

[19] N. K. Petrova and Y. A. Nefedyev, 2017 "The software complex for computer simulating the observation of stars from the lunar surface and calculating their selenographical coordinates SGEM", 2017, vol. 17, no. 21 ed T. Abdulmjanov, A. Zagidullin and A. Andreev, pp. 687-694.

[20] N. K. Petrova and Y. A. Nefedyev, "Developing software processor to carry out analytical operations with trigonometric series by OOP method", SGEM, 2018, vol. 18, no. 21 ed D Lootfullin, A Zagidullin and A Andreev, pp. 301-308.

[21] S.B. Ognivtsev, "Concept of a digital platform for agroindustrial complex", International agricultural journal, 2018, no. 2, pp. 16-23.

[22] S.G. Salnikov, "Actual directions of the digital transformation of the Russian agricultural sector" [Electronic resource]. Available at: http://www.viapi.ru/.
[6] M. Guerra, "3 Ways the IoT Revolutionizes Farming", Electronic

[7] "Is Artificial Intelligence Agriculture the Way of the Future?", Synthetic 